\title{
Spectral Behavior of Pinus elliottii, Subjected to Drought in Southern Brazil
}

\author{
Géssyca Fernanda de Sena Oliveira ${ }^{1}$, Uilian do Nascimento Barbosa ${ }^{1}$, José Jorge Monteiro Junior ${ }^{1}$, \\ Diogo José Oliveira Pimentel ${ }^{1}$, Julianne Moura da Silva ${ }^{1}$, Lorena de Moura Melo ${ }^{1}$, Giselle Lemos Moreira ${ }^{1}$, \\ Gabriela Salami ${ }^{1}$, Tamires Leal de Lima ${ }^{1}$, Pierre André Bellé ${ }^{2}$, Elisiane Alba ${ }^{2}$, Emanuel Araújo Silva ${ }^{1}$, \\ Rudiney Soares Pereira ${ }^{1} \&$ Adriano Castelo dos Santos ${ }^{1}$ \\ ${ }^{1}$ Departamento de Ciência Florestal, Universidade Federal Rural de Pernambuco, Recife, Brazil \\ ${ }^{2}$ Departamento de Ciência Florestal, Universidade Federal de Santa Maria, Santa Maria, Brazil \\ Correspondence: Adriano Castelo dos Santos, Departamento de Ciência Florestal, Universidade Federal Rural de \\ Pernambuco, Recife, Brazil. Tel: 96-981-407-208. E-mail: adrianocasteloeng@gmail.com
}

Received: September 9, 2019

Accepted: November 7, 2019

Online Published: December 15, 2019

doi:10.5539/jas.v12n1p179

URL: https://doi.org/10.5539/jas.v12n1p179

\begin{abstract}
The second most cultivated plant to a forest range in Brazil is the Pinus elliottii. This paper aims to evaluate the spectral behavior of individuals of Pinus elliottii in the electromagnetic radiation $\left(1^{\text {st }}\right)$ of the visible and $\left(2^{\text {nd }}\right)$ the infrared, when submitted to the water deficit. The experiment was conducted in the city of Santa Maria located at the Rio Grande do Sul State. The spectral responses of 10 individuals of Pinus elliottii were observed in different climatic seasons at 24 months of age. To evaluate the spectral behavior a spectroradiometer was used, and the behavior in the 450 to $1700 \mathrm{~nm}$ range was analyzed. Five individuals were submitted to water deficit treatment and five were used as controls, remaining in adequate water conditions. The spectral pattern for individuals submitted to water deficit was similar, but a trend of wavelength responses in the region of visible green $(577-491 \mathrm{~nm})$ and near-infrared (1100-789 nm) was noticeable. The most evident differences occurred in the fall season when differences in spectral amplitudes are noticeable and significantly different from the rest of the year.
\end{abstract}

Keywords: remote sensing; stress in plants; leaf optical properties; reflectance spectra

\section{Introduction}

Species of the Pinus genus, exotic to the Brazilian flora, are being widely used by the timber industry as immediate substitutes of our native woods (Pelozzi et al., 2012). Pinus elliottii, also known as American pine, is one of the species widely used in Brazil. Native to the southeastern US, it is widely used in furniture, pulp, and paper, as well as construction, but the wood produced is generally of low quality and small size due to the absence of management (Spathelf \& Seling, 2000).

The cultivation of Pinus species in the southern region of Brazil has been increasing due to the favorable climate of this region (Georgin, 2014). In Rio Grande do Sul, for example, Pinus elliottii is one of the largest in terms of planting area, being used in construction, furniture manufacturing and resin production (Floriano et al., 2009).

Sustainable forest management has been recommended by foresters for some three centuries and any analysis of the feasibility of forest development programs should be considered as a prerogative (Floriano et al., 2009).

When initiating a reforestation process, there is a need to evaluate and monitor it to see if the proposed goals and objectives are being met (Campos \& Martins, 2016). Thus, it is imperative that the evaluations be carried out in regular time spaces, in order to avoid the occurrence of unforeseen events that may jeopardize the process (Miranda Neto et al., 2012), eliminating errors and surplus costs immediately and favoring the evolution of it. For this reason, forest researchers study and develop methods to quantify production, providing the development of techniques that aim to increase yield and reduce costs (Schneider, 1999). The use of Remote Sensing has been shown to be quite feasible with regard to the evaluation of environments that present the need for monitoring (Lersch, 2003).

The association between the data of Remote Sensing with objects on the Earth's surface comprises the process of interaction of the electromagnetic radiation with the target under study (Ponzoni et al., 2018). This relation can 
be expressed by reflectance values. They consist of physical variables and allow to relate the spectral data to the parameters located in the field (Ponzoni et al., 2012).

The reflectance spectroradiometry has the function of measuring the reflected electromagnetic energy of the surface of the objects at different wavelengths and representing them in a graphical form, called the spectral reflectance curve (Meneses \& Madeira Netto, 2001).

In forestry science, several projects have demonstrated their ability to identify and monitor physiological changes in forests (Blackburn, 2002), since plants emit and reflect electromagnetic radiation and are captured by special sensors that are sensitive to certain wavelengths (Lippert et al., 2015). This information corroborates the determination of the physiological state of the vegetation, as well as the detection of stress, discrimination of phenological characteristics, measurement and interpretation of the amount of photosynthetically active radiation absorbed (Ferri et al., 2004).

Thus, the objective of this work was to evaluate the spectral behavior of individuals of Pinus elliottii when submitted to a water deficit situation.

\section{Material and Methods}

\subsection{Description of the Area}

According to the classification of Köppen, the climate of the region is classified as Cfa, subtropical humid, without dry season and with average temperatures ranging from $14.3{ }^{\circ} \mathrm{C}$ in the winter to $26.3{ }^{\circ} \mathrm{C}$ in summer and average precipitation rotating around $1400 \mathrm{~mm}$ per year.

\subsection{Data Collection and Analysis}

Data collection was performed during the fall and spring seasons. The dry simulation cycles were 45 days each.

The first collection was carried out between September and October 2014, while the second, between March and April 2015.

The spectral responses of 10 individuals of Pinus elliottii at 24 months of age were observed, so that five individuals were submitted to treatment of water deficit and five were used as witnesses, remaining in adequate water conditions.

For the second cycle, the same control individuals used in the previous cycle were maintained, and another five individuals were used in the treatment condition (Figure 1).

In general, the individuals presented a low size, since they were conditioned in sandy soil, with the limitation of nutrients, besides the low rainfall index.

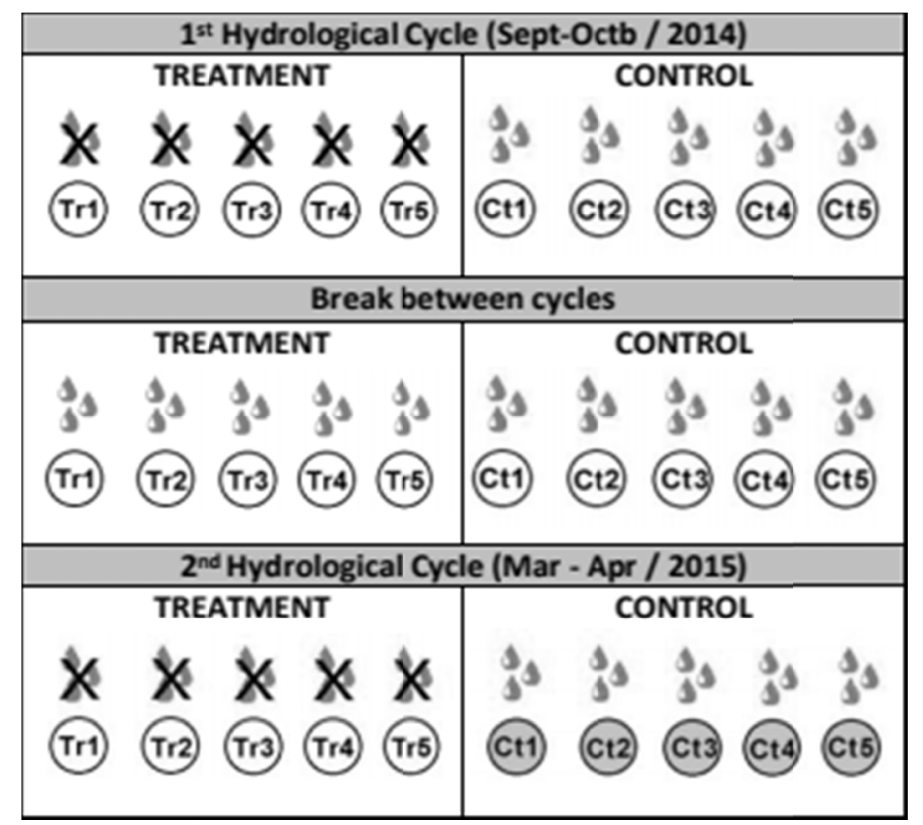

Figure 1. An experiment performed with individuals of Pinus elliottii maintained on adequate water conditions (control) and submitted to water deficit (treatment) 
The spectral data were collected using the FieldSpec ${ }^{\circledR} 3$ spectroradiometer model RST 3ZC (Analytical Spectral Devices, Inc., USA). The spectral range analyzed was between 400 and $1700 \mathrm{~nm}$. The calibration was performed by means of a standard reference plate before the measurement of the reflectance value of the different species. Two readings were made in young tissue (apical portion) and two in mature tissue, aiming to better represent the species under study. The readings were performed between 11:00 p.m. and 1:00 p.m. by virtue of the period of greatest radiation intensity. The arithmetic means of the samples collected in each individual was obtained and afterwards, the partial derivatives analysis (Equation 1) was performed, using the first derivative. The derivative analysis was included in the procedures, in order to obtain the enhancement of features that stand out in the spectral behavior of the target.

$$
\frac{\mathrm{ds}}{\mathrm{d} \lambda}=\left|\frac{\mathrm{s}\left(\lambda_{\mathrm{i}}\right)-\mathrm{s}\left(\lambda_{\mathrm{j}}\right)}{\Delta \lambda}\right|
$$

Where, "ds" is the spectral derivative; "s" is the reflectance value at the initial (i) and final (j) wavelengths; " $\Delta \lambda$ " corresponds to the difference of the wavelengths (in this study, the value 1 is constant in the equation).

The differences in wave behavior were verified from the Wilcoxon Rank test $(\alpha=0.05)$, which made use of the "paired = TRUE" argument in the Wilcox.test function (R Development Core Team, 2017). Considered appropriate for result of dependent samples.

\section{Results}

The mean comparison test did not show a statistical difference between the spring and autumn seasons for the controls, however, there was a significant difference between the treatments of water deficit. Differences were observed between the treatment and the control only in the autumn season (Figure 2). Regarding the behavior of spectral waves, the largest differences are observed in the region of the visible green $(577-491 \mathrm{~nm})$, near infrared $(1100-789 \mathrm{~nm})$ and the smallest infrared $(1100-1300 \mathrm{~nm})$ wavelengths (Figure 3).

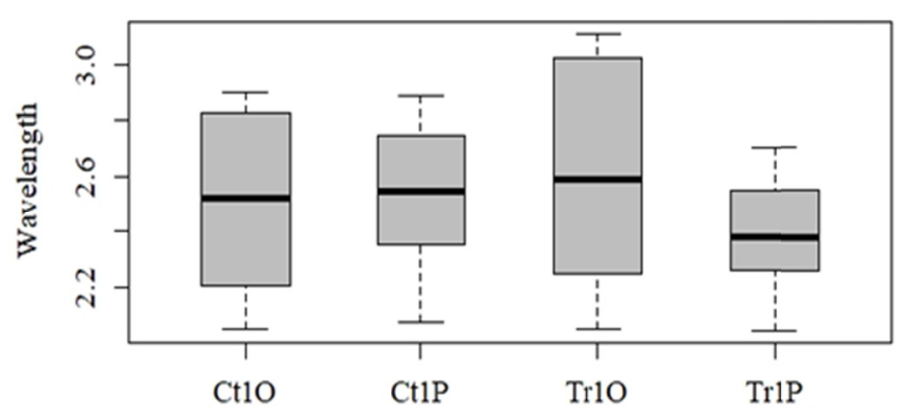

Figure 2. Box plots of the differences in the change in displacement of the medium wavelengths (visible to mid-infrared region violet). The boxes show the interquartile ranges with the median (centerline); the lower and upper limits on these indicate the minimum and maximum values. Significant differences are indicated by asterisks $(* *)$ between the averages of different individuals (Te1O, Te1P, and $\operatorname{Tr} 1 \mathrm{O} \operatorname{Tr} 1 \mathrm{P})$

$$
\text { by Rank Wilcoxon test }(\alpha=0.05)
$$




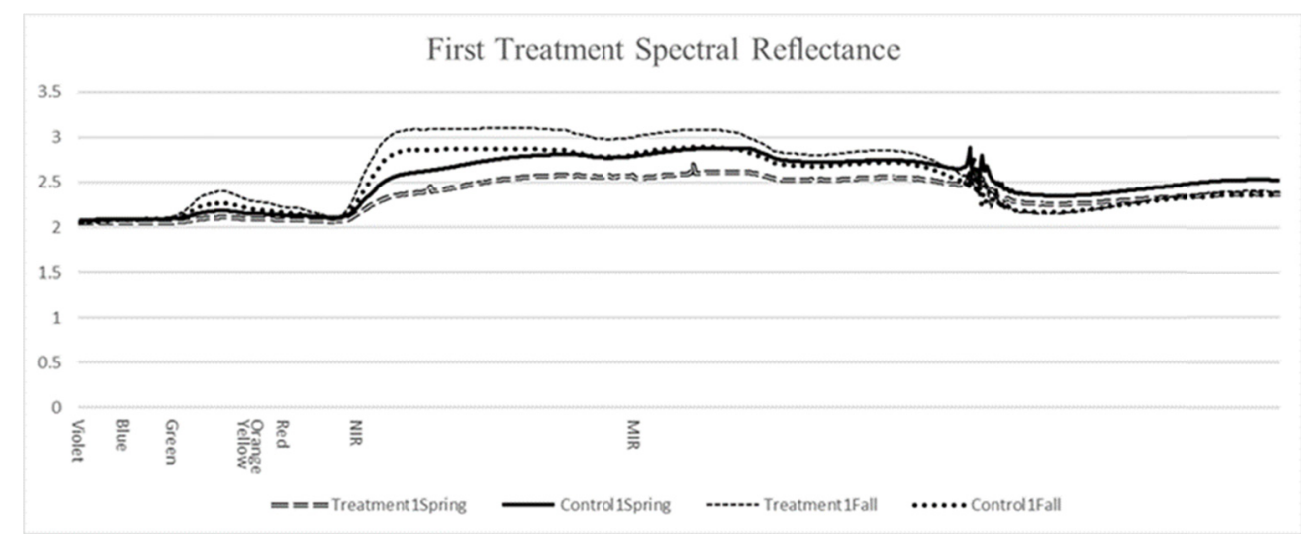

Figure 3. Derived from the spectral reflectance of the first repeat of $P$. elliottii individuals, subjected to drought and under optimum conditions, during spring and fall, in the wavelength range of 400 to $1700 \mathrm{um}$

Regarding the third repetition, there was no significant difference between the controls, however, these differed with the treatments, which in turn presented a significant difference between them (Figure 4). The behavior of the spectral waves with the largest differences was again observed in the visible green and yellow regions, in the near infrared and in the smaller infrared wavelengths (Figure 5).

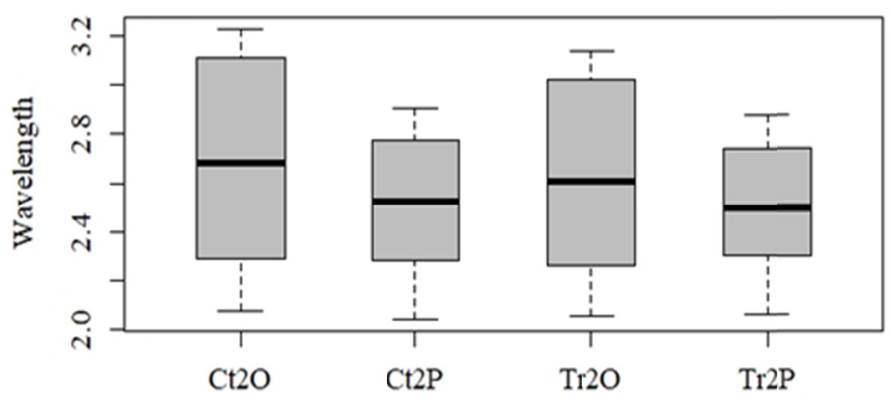

Figure 4. Box plots on the differences in the change in mean displacement of wavelengths (region visible violet to medium infrared). The boxes show the interquartile ranges with the median (centerline); the lower and upper limits on these indicate the minimum and maximum values. Significant differences are indicated by asterisks $(* *)$ between the means of the different individuals ( Te2O, Te2P, Tr2O, and $\operatorname{Tr} 2 \mathrm{P})$

by the Wilcoxon Rank test $(\alpha=0.05)$

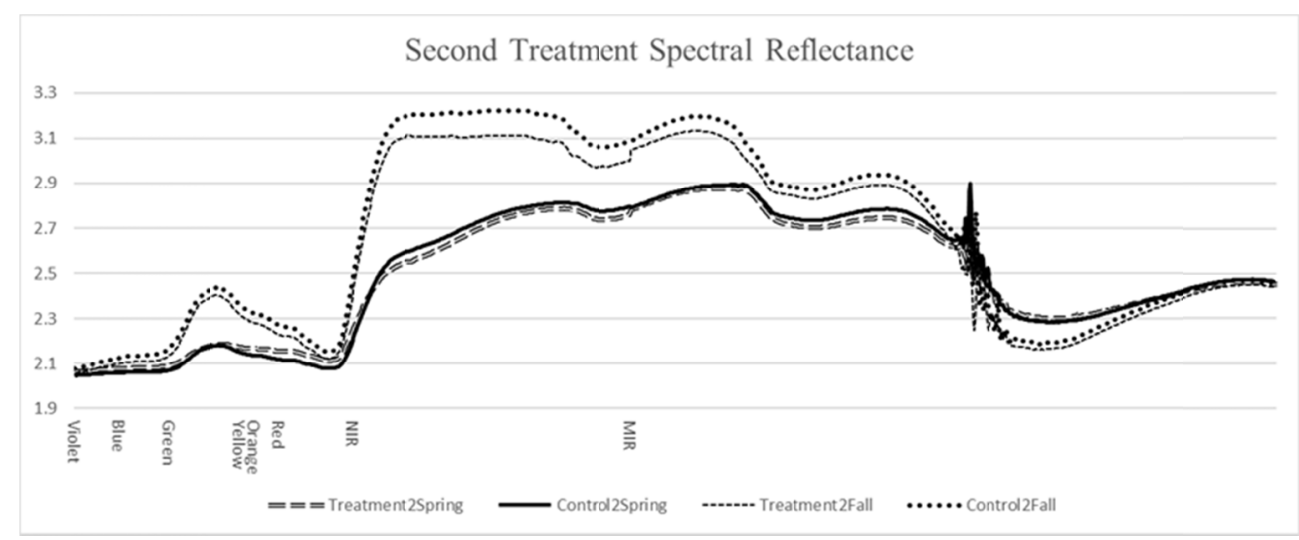

Figure 5. Reflectivity derived from the second repetition of individuals of $P$. elliottii, subjected to drought and under ideal conditions, during the spring and fall, in the wavelength range of 400 to $1700 \mathrm{um}$ 
In the fourth replicate of individuals, the control and treatment did not differ significantly either in the fall or in the spring. However, they presented differences between them, confirming the influence of the season of the year under the analysis of the water deficit (Figure 6). Such behavior can be observed, clearly, in the spectral waves (Figure 7).

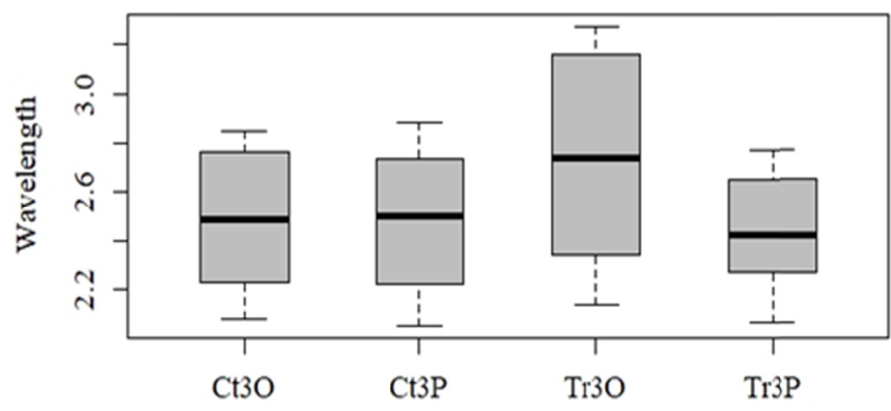

Figure 6. Box plots on the differences in the shift in mean wavelengths (region visible violet to medium infrared). The boxes show the interquartile ranges with the median (centerline); the lower and upper limits on these indicate the minimum and maximum values. Significant differences are indicated by asterisks $(* *)$ between the means of the different individuals (Te3O, Te3P, Tr3O, and Tr3P) by the Wilcoxon Rank test $(\alpha=0.05)$

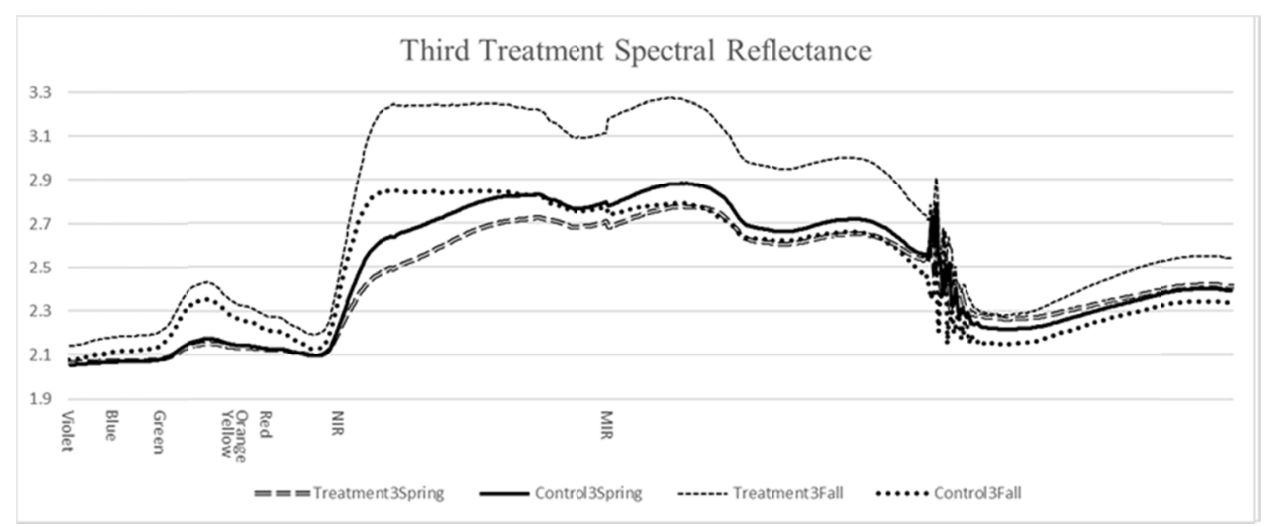

Figure 7. Derived from the spectral reflectance of the third repetition of $P$. elliottii individuals, subjected to drought and under optimum conditions, during the spring and fall, in the wavelength range of 400 to 1700

There was a significant difference between the controls and treatments in the fifth repetition (Figures 8 and 9) of individuals at both stations (Figure 10). In contrast to the other repetitions, in the behavior of spectral waves the greatest differences were observed in the region of visible green, yellow, part of red, near infrared and practically all the average infrared (Figure 11). 


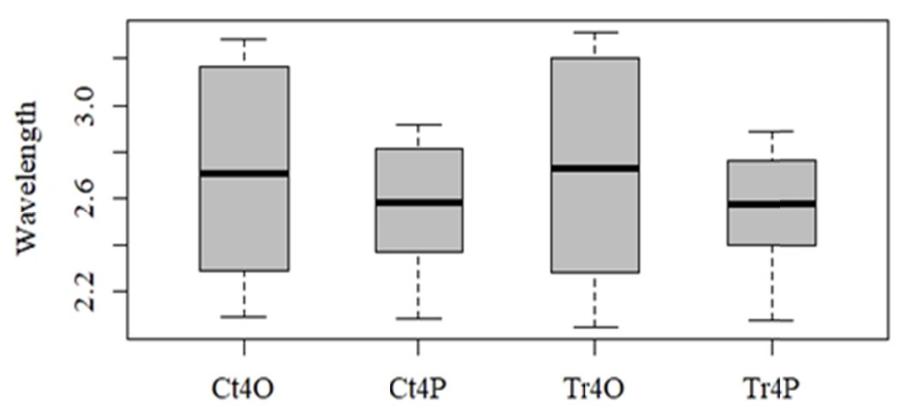

Figure 8. Box plots on the differences in the shift in mean wavelengths (visible violet to medium infrared region). The boxes show the interquartile ranges with the median (centerline); the lower and upper limits on these indicate the minimum and maximum values. Significant differences are indicated by asterisks $(* *)$ between the means of the different individuals (Te4O, Te4P, Tr4O, and Tr4P) by the Wilcoxon Rank test $(\alpha=0.05)$.

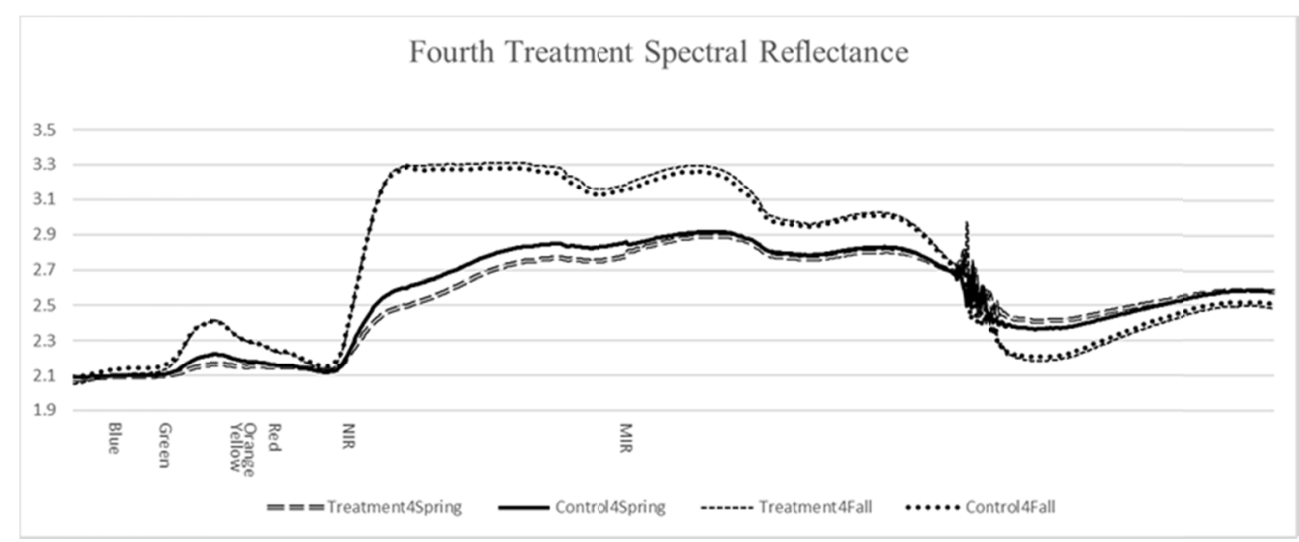

Figure 9. Derived from the spectral reflectance of the fourth repetition of $P$. elliottii individuals, subjected to drought and under ideal conditions, during spring and fall, in the wavelength range of 400 to $1700 \mathrm{um}$

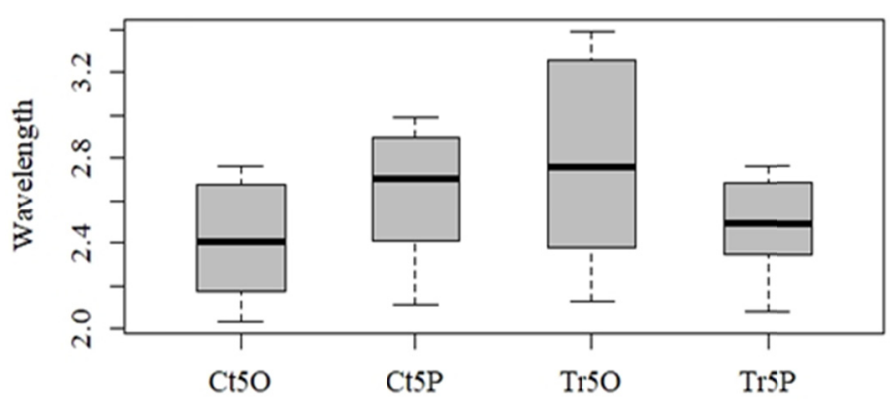

Figure 10. Box plots on the differences in the shift in mean wavelengths (visible violet region to medium infrared). The boxes show the interquartile ranges with the median (centerline); the lower and upper limits on these indicate the minimum and maximum values. Significant differences are indicated by asterisks $(* *)$ between the means of the different individuals (Te5O, Te5P, Tr5O, and Tr5P) by the Wilcoxon Rank test $(\alpha=0.05)$ 


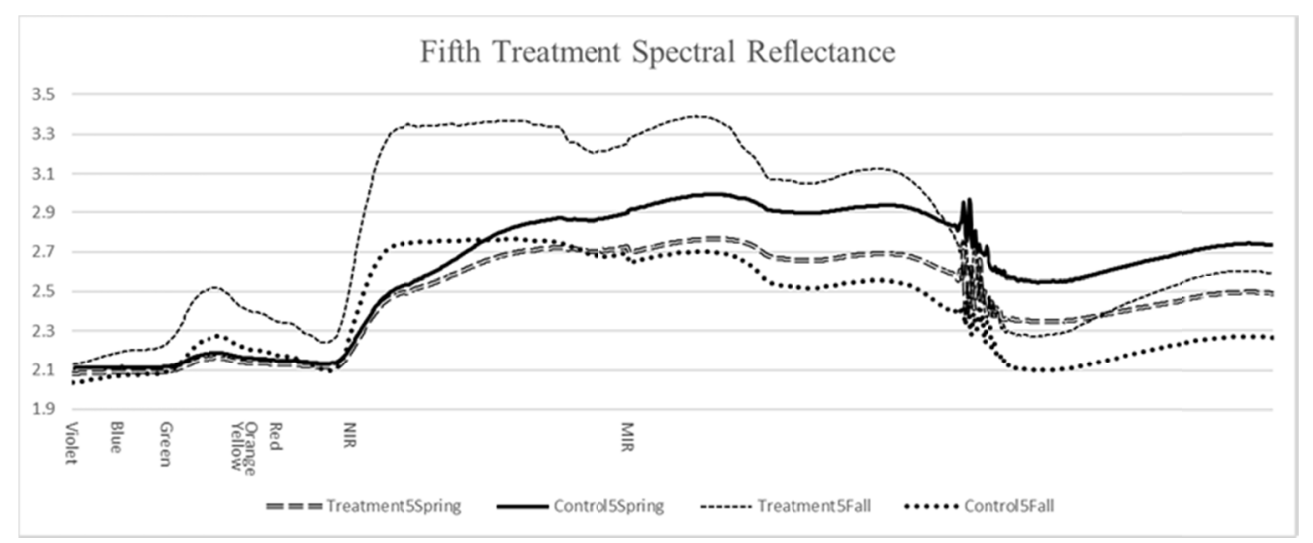

Figure 11. Spectral reflectance derivative of the fifth repetition of $P$. elliottii individuals, subjected to drought and under optimum conditions, during spring and fall, in the wavelength range of 400 to $1700 \mathrm{um}$

In the multidimensional analysis, the spectral responses in the visible region respond in a similar way to the Near Infrared (NIR) (Figure 12). However, the BTI shows a better response, since it is closer to the $\mathrm{x}$-axis and accounts for $79.9 \%$ of the data. In addition, it is interesting to combine the use of the NIR with the Medium Infrared (MIR), since both are more associated to each of the axes, being the first to the $\mathrm{x}$-axis and the second to the y-axis. It is also noted that individuals measured in the spring are more associated with the y-axis, that is, they are better interpreted by the MIR. On the other hand, the individuals measured in the month of October, mainly the treatments, were better interpreted by the NIR.

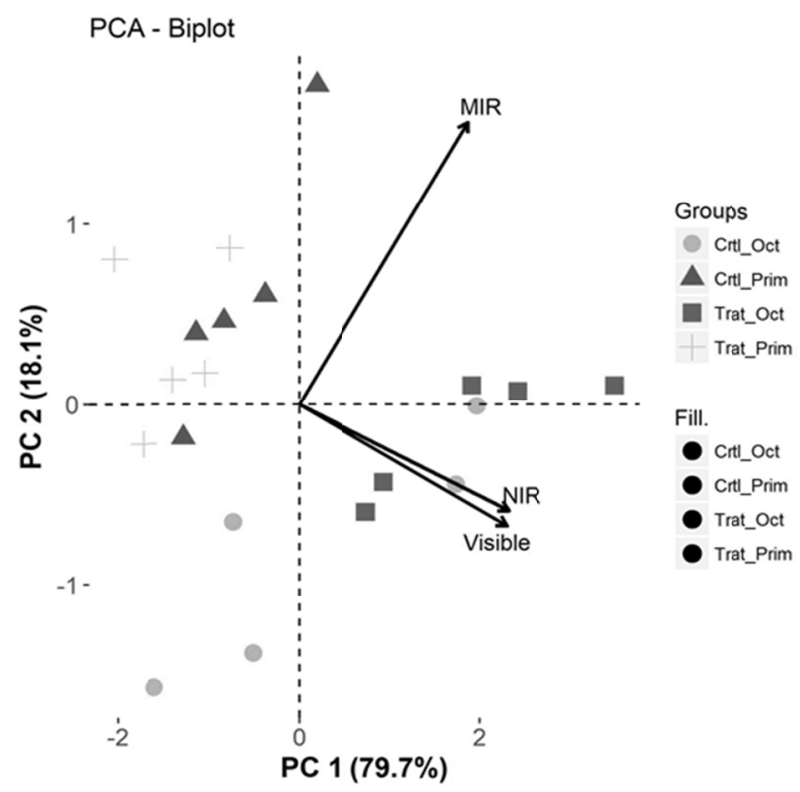

Figure 12. Multidimensional PCA ordering of different wavelengths in the visible, near infrared and medium infrared regions in individuals of P. elliottii during autumn and spring, Rio Grande do Sul, Brazil

\section{Discussion}

Studying the surface reflectance and the Normalized Difference Vegetation Index (NDVI) of a canopy of Pinus elliottii Engelm. Berra et al. (2014) found that the spectral behavior of P. elliottii showed a larger amplitude in the medium infrared (MIR) followed by the near infrared (NIR). Orué (2002) working with ETM+/Landsat 7 in stands of Pinus spp. in the province of Missiones, Argentina $\left(26^{\circ} 12^{\prime} \mathrm{S}, 54^{\circ} 19^{\prime} \mathrm{O}\right)$, observed this same pattern. These results are the opposite of the results found in the present study since the largest amplitudes were found in the NIR, mainly in the initial range $(1200 \mathrm{~nm})$. 
When analyzing the spectral behavior of vegetation in different successional stages Ponzoni and Rezende (2004) observed that the average infrared spectral response is less perceptive in the early successional stages, while the near infrared presented a better response to the intermediate stages. These results justify the pattern observed in the present study, considering that individuals presented a mean age of 24 months.

In relation to the visible region, Berra et al. (2014) recommended green when they presented high values. However, Ponzoni and Shimabukuro (2010) state that the vegetation shows an evident contrast between the region of the visible and the region of the infrared, due to the photosynthetic processes of the plants. Therefore, it is recommended to prioritize the use of infrared to analyze the behavior of Pinus elliottii.

Studying the temporal variation of NDVI in Juiz de Fora, Ramos (2016) observed that the highest values of NDVI were found in summer, followed by autumn, spring, and local winter. This same spectral behavior was observed by Araujo et al. (2015) studying corn crop. Other works (Fragal et al., 2006; Magalhães et al., 2013) recommend performing the spectral behavior in vegetation during the summer.

Comparing seasonal period in eucalyptus plantation, Brandelero (2010) observed significant differences between seasons, but none of the averages were completely different, pointing out similarities in autumn, winter, and spring; occurring the same for the averages of autumn, winter, and summer.

Analyzing the spectral response of Eucalyptus globulus (Labill.) Leaves attacked by Mycosphaerella spp., Lippert et al. (2015) observed that in both the visible and the infrared regions, autumn showed greater variations between infestation levels when compared to spring.

\section{Conclusion}

The spectral pattern for individuals submitted to water deficit was similar since the spectral behavior at the same stations does not change significantly. In contrast, a tendency of the wavelength responses in the region of visible green and near infrared was perceptible, since they are more efficient as well as more evident, especially in the fall season.

We suggest the replication of this study in the field, with the monthly frequency of the collections and for a longer period of evaluation, in order to confirm the evidence found. For more accurate validations, it is recommended to correlate physiological growth and photosynthetic variables to the spectral behavior of the culture analyzed.

\section{References}

Araujo, G. L., Almeida, T. S., Mantovani, E. C., Oliveira, L. A., \& de Azeredo, R. A. (2017). Spectral responses and analysis of normalized vegetation index (ndvi) in irrigated maize crop. Annals of the FACIG Scientific Seminar.

Berra, E. F., Fontana, D. C., \& Kuplich, T. M. (2014). Comparison of spectral reflectance and IVDN of the LISS-III/RESOURCESAT-1 and TM/LANDSAT-5 sensors in forest stands. Brazilian Journal of Cartography, 11(66/2).

Blackburn, G. A. (2002). Remote sensing of forest pigments using airborne imaging spectrometer and LIDAR imagery. Remote Sensing of Environment, 82(2-3), 311-321. https://doi.org/10.1016/S0034-4257(02) 00049-4

Brandelero, C. (2010). Spectroradiometry of the visible and near infrared in Eucalyptus grandis W. Hill ex Maiden stands (Doctoral Thesis, Universidade Federal de Santa Maria, Brazil).

Campos, W. H., \& Martins, S. V. (2016). Natural regeneration stratum as an indicator of restoration in area of environmental compensation for mining limestone, municipality of Barroso, MG, Brazil. Revista Arvore, 40(2), 189-196. https://doi.org/10.1590/0100-67622016000200001

Ferri, C. P., Formaggio, A. R., \& Schiavinato, M. A. (2004). Narrow band spectral indexes for chlorophyll determination in soybean canopies [Glycine max (L.) Merril]. Brazilian Journal of Plant Physiology, 16(3), 131-136. https://doi.org/10.1590/S1677-04202004000300002

Floriano, E. P., Schneider, P. R., Finger, C. A. G., \& Fleig, F. D. (2009). Economic analysis of the production of Pinus elliottii in the Southeast, Rio Grande do Sul. Ciência Florestal, 19(4), 393-406. https://doi.org/ $10.5902 / 19805098895$

Fragal, E. H., Novo, E. M. L. M., \& Silva, T. S. F. (2015). Analysis of spectral bands and indices of vegetation NDVI and NBR for the historical reconstruction of the alteration of lowland Amazon forest through temporal series Landsat, João Pessoa. XVII Brazilian Symposium of Remote Sensing (BSRS). 
Georgin, J. (2014). Pinus elliottii plantation on small farms in northern Rio Grande do Sul. Revista Monografias Ambientais, 13(3), 3341-3345. https://doi.org/10.5902/2236130813371

Lippert, D. B., Benedetti, A. C. P., Muniz, M. F. B., Pereira, R. S., Junior, C. A. B., Finkenauer, E., \& Berra, E. F. (2015). Comportamento espectral de folhas de Eucalyptus globulus (Labill.) atacadas por Mycosphaerella spp. nas regiões do visível e do infravermelho próximo do espectro eletromagnético. Ciência Florestal, 25(1), 211-219. https://doi.org/10.5902/1980509817479

Magalhães, I. A. L. (2013). Characterization of forest dynamics temporal spectrum of sugarcane in the municipality of Itapemirim, ES (Master's thesis, Universidade Federal do Espírito Santo, Brazil).

Neto, A. M., Martins, S. V., de Almeida Silva, K., \& Gleriani, J. M. (2012). Ecological relations between strata of a restored area, at the age of 40, Viçosa-MG. Forest and Enviromental Journal, 19(4), 393-404. https://doi.org/10.4322/floram.2012.050

Orué, N. E. (2002). Estimation of Pinus spp. using data from the Landsat 7 satellite.

Pelozzi, M. M. A., Severo, E. T. D., Calonego, F. W., \& Rodrigues, P. L. M. (2012). Physical properties of juvenile and mature woods of Pinus elliottii Engelm var. Elliottii and Eucalyptus grandis Hill ex Maiden. Ciência Florestal, 22(2), 305-313. https://doi.org/10.5902/198050985737

Ponzoni, F. J. (2002). Remote sensing in the study of vegetation: Diagnosing the Atlantic forest. São José dos Campos, Brazil: National Institute of Space Research.

Ponzoni, F. J., \& Rezende, A. C. P. (2004). Spectral characterization of successional stages of secondary arboreal vegetation in Altamira (PA), using orbital data. Revista Árvore, 28(4), 535-545. https://doi.org/10.1590/ S0100-67622004000400007

Ramos, M. F., de Melo Ribeiro, C. B., \& de Andrade, M. P. (2016). Study of temporal variation in the vegetation index normalized difference in Juiz de Fora from satellite images. Revista de Geografia, 6(1).

Schneider, P. R., \& Oesten, G. (1999). Auxiliary tables for the management of Pinus elliottii and Araucaria angustifolia for the medium di okabakti region of Rio Grande do Sul. UFSM, Santa Maria.

Spathelf, P., \& Seling, I. (2000). Economic effects of different thinning programs on stands of Pinus elliottii. Ciência Florestal, 10(1), 21-44. https://doi.org/10.5902/19805098393

\section{Copyrights}

Copyright for this article is retained by the author(s), with first publication rights granted to the journal.

This is an open-access article distributed under the terms and conditions of the Creative Commons Attribution license (http://creativecommons.org/licenses/by/4.0/). 